\title{
Towards personalized medicine in sepsis: Quest for Shangri-La?
}

\author{
Ayan Sen ${ }^{1,2}$ and Sachin Yende ${ }^{* 1,2}$ \\ University of Pittsburgh Department of Critical Care Medicine: Evidence-Based Medicine Journal Club, edited by Sachin Yende
}

\begin{abstract}
Expanded abstract Citation

Boomer JS, To K, Chang KC, Takasu O, Osborne DF, Walton AH, Bricker TL, Jarman SD 2nd, Kreisel D, Krupnick AS, Srivastava A, Swanson PE, Green JM, Hotchkiss RS: Immunosuppression in patients who die of sepsis and multiple organ failure. JAMA 2011, 306:2594-2605.
\end{abstract}

\section{Background}

Severe sepsis is typically characterized by initial cytokinemediated hyper-inflammation. Whether this hyperinflammatory phase is followed by immunosuppression is a subject of controversy. Animal studies suggest that multiple immune defects occur in sepsis, but data from humans remain conflicting.

\section{Methods}

Objectives: To determine the association of sepsis with changes in host innate and adaptive immunity and to examine potential mechanisms for putative immunosuppression.

Design: Rapid prospective postmortem spleen and lung tissue harvest and analysis within 120 minutes of death.

Setting: Intensive care units (ICUs) of academic medical centers.

Subjects: A convenience sample of 40 patients who died with active severe sepsis was taken over the course of 2 years to characterize their immune status at the time of death. Control spleens $(n=29)$ were obtained from patients who were declared brain dead or had emergent splenectomy due to trauma; control lungs $(n=20)$ were obtained from transplant donors or from lung cancer resections.

\footnotetext{
*Correspondence: yendes@upmc.edu

'The Clinical Research, Investigation, and Systems Modeling of Acute IIIness (CRISMA) Center, University of Pittsburgh, Scaife Hall, 3550 Terrace Street, Pittsburgh, PA 15261, USA

Full list of author information is available at the end of the article
}

Interventions: None.

Outcomes: Cytokine secretion assays and immunophenotyping of cell surface receptor-ligand expression profiles were performed to identify potential mechanisms of immune dysfunction. Immunohistochemical staining was performed to evaluate the loss of immune effector cells.

\section{Results}

The mean ages (standard deviations) of patients with sepsis and controls were 71.7 (15.9) and 52.7 (15.0) years, respectively. Patients with sepsis were in the ICU for a median of 8 days (range of 1 to 195 days), whereas control patients were in the ICU for not more than 4 days. The median duration of sepsis was 4 days (range of 1 to 40 days). Anti-CD3/anti-CD28-stimulated splenocytes from patients with sepsis, compared with those from controls, had significant reductions in cytokine secretion at 5 hours: tumor necrosis factor, 5,361 (95\% confidence interval (CI) 3,327 to 7,485) pg/ $\mathrm{mL}$ versus 418 ( $95 \% \mathrm{CI} 98$ to 738$) \mathrm{pg} / \mathrm{mL}$; interferongamma, 1,374 (95\% CI 550 to 2,197$) \mathrm{pg} / \mathrm{mL}$ versus 37.5 (95\% CI -5 to 80$) \mathrm{pg} / \mathrm{mL}$; interleukin-6, 3,691 (95\% CI 2,313 to 5,070 ) versus 365 ( $95 \%$ CI 87 to 642 ) $\mathrm{pg} / \mathrm{mL}$; and interleukin-10, 633 (95\% CI -269 to 1,534) versus 58 (95\% CI -39 to 156$) \mathrm{pg} / \mathrm{mL}(P<0.001$ for all). There were similar reductions in 5-hour lipopolysaccharidestimulated cytokine secretion. Cytokine secretion in patients with sepsis was generally less than $10 \%$ of that in controls, independently of age, duration of sepsis, corticosteroid use, and nutritional status. Despite differences between spleen and lung, flow cytometric analysis showed increased expression of selected inhibitory receptors and ligands and expansion of suppressor cell populations in both organs. Unique differences in cellular inhibitory molecule expression existed in immune cells isolated from lungs of patients with sepsis versus patients with cancer and versus transplant donors. Immunohistochemical staining showed extensive depletion of splenic CD4, CD8, and HLA-DR cells and expression of ligands for inhibitory receptors on lung epithelial cells. 


\section{Conclusions}

Patients who die in the ICU following sepsis compared with patients who die of non-sepsis etiologies have biochemical, flow cytometric, and immunohistochemical findings consistent with those of immunosuppression. Targeted immune-enhancing therapy may be a valid approach in selected patients with sepsis.

\section{Commentary}

In 1992, the American College of Chest Physicians and Society of Critical Care Medicine consensus conference defined sepsis as the systemic inflammatory response syndrome occurring as a result of infection [1]. Clinical and immunologic discoveries have challenged this view of a hyper-inflammatory state, described as a 'cytokine storm' [2,3], in light of the failure of anti-inflammatory mediators, such as high-dose corticosteroids, tumor necrosis factor (TNF) antagonists, and interleukin-1 (IL-1) pathway inhibitors, to improve survival [4-6]. Subsequent theories have proposed that some patients may be immunosuppressed and the compensatory anti-inflammatory response syndrome may predominate [7-9], leading to secondary infections and reactivation of dormant viruses $[10,11]$. These findings have been based largely on experimental murine sepsis models $[12,13]$ and small human studies, in which most measurements were obtained in the circulation.

Boomer and colleagues [14] conducted a comprehensive assessment of immune dysfunction in human subjects who died of sepsis and multi-organ failure. Rather than focusing on circulating markers alone, the authors examined markers in tissues, including lungs since they are a common site for secondary infections. The authors identified multiple inhibitory mechanisms to explain the occurrence of immunosuppression, including dominance of inhibitory over activating receptors, expansion of suppressive cell types, and induction of inhibitory ligands on both antigen-presenting cells and tissue parenchymal cells.

\section{Reduced expression of inflammatory cytokines}

The authors confirmed that immunosuppression occurs within tissues, and expression of key inflammatory markers, such as TNF- $\alpha$, interferon-gamma (IFN- $\gamma$ ), and IL-6 and IL-10, was significantly decreased when splenocytes and cells from the lung were stimulated with anti-CD3/CD28, lipopolysaccharide, and phorbol esters.

\section{Expansion of suppressor cell type}

Regulatory $\mathrm{T}\left(\mathrm{T}_{\text {reg }}\right)$ cells, which suppress immune response, were increased in the spleen of patients with sepsis, and increased expression of cells with suppressor phenotype (myeloid-derived suppressor cells) was noted in the lung tissue.

\section{Dominance of inhibitory over activating receptors and} induction of inhibitory ligands

There was reduced expression of CD28, a co-stimulatory signal that activates $\mathrm{T}$ cells and increases expression of PD-1 membrane protein. PD-1 negatively regulates Thelper and cytotoxic cell proliferation in both lung and spleen. CTLA-4, a protein receptor that downregulates the immune system, was increased, whereas IL-7Ra, which mediates cell survival, was reduced in T cells, indicating dominance of inhibitory over activating receptors.

\section{Antigen-presenting cells}

HLA-DR, a receptor that presents peptide antigens to the immune system for the purpose of eliciting T-cell response, was noted to be reduced. Immunohistochemistry showed intense airway epithelial staining for herpes virus entry mediator (HVEM) and the receptor ligand for BTLA (a B- and T-cell attenuator protein expressed on $\mathrm{T}$ cells mediating inhibitory function) on lung isolated from the majority of patients with sepsis. This is described mechanistically to mediate local immunosuppressive response in the lung in both pneumonia- and non-pneumonia-associated sepsis.

This is a novel study and provides clinical confirmation of previous experimental work showing profound immunosuppression in sepsis. Several findings of the study have important clinical implications. For instance, recovery of cytokine secretion at 22 hours was comparable for patients with sepsis and controls when removed from a septic milieu and suggests that immunosuppression may be reversible and indicates potential therapeutic possibilities.

This study has limitations. Despite an exhaustive assessment of immune markers, the sample size was small. There was significant heterogeneity in the microbiologic etiology of patients with sepsis and control patients (transplant, trauma, and neurologic devastation). Whether results of this study can be generalized to most critically ill patients with sepsis is not clear. For example, sepsis patients who were alive were not included as a control group as it is difficult to obtain tissue specimens in these patients. Many subjects in this study had a long intensive care unit course (range of 1 to 195 days) and represent those with prolonged critical illness $[15,16]$.

Finally, several questions regarding immunosuppression remain poorly understood. What is its time course, and is it a dynamic process? Increased inflammation and immunosuppression may occur concurrently, and some studies suggest that immunosuppression may occur as early as hospital presentation. Which factors affect immunosuppression? The authors found no difference across age, duration of sepsis, and nutritional status. Given the small sample size, the effect of these and other 
factors could not be assessed. Finally, whether measurements of immune markers in the tissues mirror those in the circulation is unclear. Many of the assays described in this study are not standardized and are difficult to deploy in large multi-center clinical trials.

What are the study's implications for the design of personalized strategies for patients with sepsis? First, recovery of cytokine secretion at 22 hours was comparable for patients with sepsis and controls when removed from a septic milieu. These findings and a proof-of-concept study by Meisel and colleagues [17] suggest that immunosuppression could be reversed. Second, using anti-inflammatory agents, such as glucocorticoids, for all patients with sepsis may not be appropriate, and targeted therapy based on the state of their immune function should be considered. Several therapies may improve immunosuppression. These therapies could work on multiple pathways, such as IFN- $\gamma$, or target specific pathways, such as PD-1 [18]. Instead of prior approaches in which these therapies are administered to broad populations, personalizing these therapies on the basis of immune profiles should be considered.

\section{Conclusions}

Sepsis may represent a spectrum of dynamic immunologic changes, which, if measurable, can direct therapies based on the preponderant mechanism. A subset of patients may still benefit from anti-inflammatory therapies, whereas others may respond to immunostimulatory therapies. The stage is set for making further strides toward personalizing 'immune therapy in sepsis', hitherto a Shangri-La for clinicians and sepsis investigators.

\section{Abbreviations}

IFN- $\gamma$, interferon-gamma; IL, interleukin; TNF, tumor necrosis factor.

\section{Competing interests}

The authors declare that they have no competing interests.

\section{Author details}

'The Clinical Research, Investigation, and Systems Modeling of Acute IIIness (CRISMA) Center, University of Pittsburgh, Scaife Hall, 3550 Terrace Street, Pittsburgh, PA 15261, USA. ${ }^{2}$ Department of Critical Care Medicine, University of Pittsburgh, Scaife Hall, 3550 Terrace Street, Pittsburgh, PA 15261, USA.

\section{Published: 11 February 2013}

\section{References}

1. Bone RC, Balk RA, Cerra FB, Dellinger RP, Fein AM, Knaus WA, Schein RM, Sibbald WJ: Definitions for sepsis and organ failure and guidelines for the use of innovative therapies in sepsis. The ACCP/SCCM Consensus Conference Committee. American College of Chest Physicians/Society of Critical Care Medicine. Chest 1992, 101:1644-1655.
2. Oberholzer A, Oberholzer C, Moldawer LL: Sepsis syndromes: understanding the role of innate and acquired immunity. Shock 2001, 16:83-96.

3. Rittirsch D, Flierl MA, Ward PA: Harmful molecular mechanisms in sepsis. Nat Rev Immunol 2008, 8:776-787.

4. Wang TS, Deng JC: Molecular and cellular aspects of sepsis-induced immunosuppression. J Mol Med (Berl) 2008, 86:495-506.

5. Fisher CJ Jr., Agosti JM, Opal SM, Lowry SF, Balk RA, Sadoff JC, Abraham E, Schein RM, Benjamin E: Treatment of septic shock with the tumor necrosis factor receptor:Fc fusion protein. The Soluble TNF Receptor Sepsis Study Group. N Engl J Med 1996, 334:1697-1702.

6. Remick DG: Cytokine therapeutics for the treatment of sepsis: why has nothing worked? Curr Pharm Des 2003, 9:75-82

7. Hotchkiss RS, Karl IE: The pathophysiology and treatment of sepsis. N Engl J Med 2003, 348:138-150.

8. Adib-Conquy M Cavaillon JM: Compensatory anti-inflammatory response syndrome. Thromb Haemost 2009, 101:36-47.

9. Bone RC: Sir Isaac Newton, sepsis, SIRS, and CARS. Crit Care Med 1996, 24:1125-1128.

10. Limaye AP, Kirby KA, Rubenfeld GD, Leisenring WM, Bulger EM, Neff MJ, Gibran NS, Huang ML, Santo Hayes TK, Corey L, Boeckh M: Cytomegalovirus reactivation in critically ill immunocompetent patients. JAMA 2008, 300:413-422.

11. Luyt CE, Combes A, Deback C, Aubriot-Lorton MH, Nieszkowska A, Trouillet JL, Capron F, Agut H, Gibert C, Chastre J: Herpes simplex virus lung infection in patients undergoing prolonged mechanical ventilation. Am J Respir Crit Care Med 2007, 175:935-942.

12. Muenzer JT, Davis CG, Chang K, Schmidt RE, Dunne WM, Coopersmith CM, Hotchkiss RS: Characterization and modulation of the immunosuppressive phase of sepsis. Infect Immun 2010, 78:1582-1592.

13. Hotchkiss RS, Coopersmith CM, McDunn JE, Ferguson TA: The sepsis seesaw: tilting toward immunosuppression. Nat Med 2009, 15:496-497.

14. Boomer JS, To K, Chang KC, Takasu O, Osborne DF, Walton AH, Bricker TL, Jarman SD 2nd, Kreisel D, Krupnick AS, Srivastava A, Swanson PE, Green JM, Hotchkiss RS: Immunosuppression in patients who die of sepsis and multiple organ failure. JAMA 2011, 306:2594-2605.

15. Opal SM: Immunologic alterations and the pathogenesis of organ failure in the ICU. Semin Respir Crit Care Med 2011, 32:569-580.

16. Monneret G, Venet F, Pachot A, Lepape A: Monitoring immune dysfunctions in the septic patient: a new skin for the old ceremony. Mol Med 2008, 14:64-78.

17. Meisel C, Schefold JC, Pschowski R, Baumann T, Hetzger K, Gregor J, WeberCarstens S, Hasper D, Keh D, Zuckermann H, Reinke P, Volk HD: Granulocytemacrophage colony-stimulating factor to reverse sepsis-associated immunosuppression: a double-blind, randomized, placebo-controlled multicenter trial. Am J Respir Crit Care Med 2009, 180:640-648.

18. Topalian SL, Hodi FS, Brahmer JR, Gettinger SN, Smith DC, McDermott DF, Powderly JD, Carvajal RD, Sosman JA, Atkins MB, Leming PD, Spigel DR, Antonia SJ, Horn L, Drake CG, Pardoll DM, Chen L, Sharfman WH, Anders RA, Taube JM, McMiller TL, Xu H, Korman AJ, Jure-Kunkel M, Agrawal S, McDonald D, Kollia GD, Gupta A, Wigginton JM, Sznol M: Safety, activity, and immune correlates of anti-PD-1 antibody in cancer. NEngl J Med 2012, 366:2443-2454.

doi:10.1186/cc12485

Cite this article as: Sen A, Yende S: Towards personalized medicine in sepsis: Quest for Shangri-La? Critical Care 2013, 17:303. 